\title{
Sneaky queens in Melipona bees selectively detect and infiltrate queenless colonies
}

\author{
Annette Van Oystaeyen ${ }^{\mathrm{a}, *}$, Denise Araujo Alves ${ }^{\mathrm{b}}$, Ricardo Caliari Oliveira ${ }^{\mathrm{a}}$, \\ Daniela Lima do Nascimento ${ }^{\mathrm{b}}$, Fábio Santos do Nascimento ${ }^{\mathrm{b}}$, Johan Billen ${ }^{\mathrm{a}}$, \\ Tom Wenseleers ${ }^{\text {a }}$ \\ a Laboratory of Socio-ecology and Social Evolution, Zoological Institute, University of Leuven, Leuven, Belgium \\ ${ }^{\mathrm{b}}$ Laboratório de Ecologia e Comportamento de Insetos Sociais, Departamento de Biologia, Faculdade de Filosofia, Ciências e Letras de Ribeirão Preto, \\ Universidade de São Paulo, Ribeirão Preto, SP, Brazil
}

\section{A R T I C L E I N F O}

\section{Article history:}

Received 1 May 2013

Initial acceptance 27 May 2013

Final acceptance 19 June 2013

Available online 30 July 2013

MS. number: 13-00368

\section{Keywords:}

guarding

Melipona scutellaris

reproductive parasitism

RFID

social parasitism

stingless bee
Insect societies are characterized by advanced cooperation, but at the same time the complexity of their colonies renders them susceptible to reproductive parasitism. Recently, a genetic study on the Brazilian stingless bee Melipona scutellaris showed that unrelated queens frequently invade and take over colonies in which the mother queen had died. In the present study, we investigated this phenomenon using radio frequency identification (RFID) tags. We confirmed that alien queen take-overs are common within this species, and demonstrated that mated queens actively seek out colonies without a queen to reproduce in. Furthermore, we found that queens only penetrate their target colonies in the evening, when guarding efficiency is significantly reduced. We hypothesize that this strategy reduces the chance of the queens being attacked by entrance guards, thus maximizing their chance of successful infiltration.

(c) 2013 The Association for the Study of Animal Behaviour. Published by Elsevier Ltd. All rights reserved.
A defining characteristic of insect societies is their advanced cooperation, but at the same time their colonies are also vulnerable to both interspecific and intraspecific social parasitism. This is because social parasites may benefit nutritionally and/or reproductively from the resources stored in the host colony and by the rearing of their offspring by their hosts (Nash \& Boomsma 2008). To keep parasites out, social insect colonies are defended by entrance guards, which admit nestmates but exclude intruders (Wilson 1971). Guards can generally discriminate nestmates from nonnestmates by using chemical cues, which are believed to be colony-specific odours that are partially genetically determined and partially environmentally acquired (Breed 1983; Stuart 1988; van Zweden \& d'Ettorre 2010). Although most studies on nestmate recognition have confirmed the ability of social insects to discriminate nestmates from non-nestmates (e.g. Breed et al. 1985; Gamboa 1986; Breed \& Page 1991; Singer \& Espelie 1992; Inoue et al. 1999; Buchwald \& Breed 2005; Jones et al. 2012), many

\footnotetext{
* Correspondence: A. Van Oystaeyen, Laboratory of Socio-ecology and Social Evolution, Zoological Institute, University of Leuven, Naamsestraat 59, Box 2466, 3000 Leuven, Belgium.

E-mail address: annette.vanoystaeyen@bio.kuleuven.be (A. Van Oystaeyen).
}

have also shown this guarding system to be imperfect. For example, in the Western honeybee, Apis mellifera, guards will accidentally allow $10-50 \%$ of alien workers to enter their hives (Downs \& Ratnieks 2000), and in the Asiatic honeybee, Apis cerana, guards are similarly inefficient in preventing non-natal reproductive workers from entering their colonies (Holmes et al. 2013). In the stingless bee Melipona asilvai, guards are partially capable of discriminating between kin and nonkin, failing only when hydrocarbon profiles are too similar (Nascimento \& Nascimento 2012). The fact that the colonies' guarding systems are often imperfect opens the door for reproductive parasitism. Indeed, over the past decade, several cases of intraspecific worker parasitism have been discovered in various groups of social insects, including bumblebees (Birmingham et al. 2004; Lopez-Vaamonde et al. 2004; Takahashi et al. 2010) and honeybees (Nanork et al. 2005, 2007; Chapman et al. 2009, 2010). These studies document cases of reproductive worker parasitism, whereby workers penetrate and parasitize nearby unrelated colonies to lay unfertilized, maleproducing eggs, which are subsequently reared by the host colony.

In contrast to intraspecific worker parasitism, studies on intraspecific queen parasitism remain scant, because it had commonly been assumed that the establishment of new colonies in highly 
eusocial bee colonies could only be achieved through swarming or supersedure of the mother queen (Michener 1974). Recently, however, a behavioural study (Sommeijer et al. 2003a) suggested intraspecific queen parasitism occurs in stingless bees of the genus Melipona, with observations of lone Melipona favosa queens attempting to take over unrelated colonies nearby. A long-term genetic study on Melipona scutellaris subsequently confirmed the occurrence of intraspecific queen parasitism in the genus Melipona, with data showing unrelated queens frequently invading and taking over colonies in which the mother queen happened to die, and with $25 \%$ of all colony take-overs being undertaken by alien queens (Wenseleers et al. 2011). The occurrence of intraspecific queen parasitism in Melipona bees may be linked with overproduction of queens in this genus (Kerr 1950; Wenseleers \& Ratnieks 2004; Santos-Filho et al. 2006). It is believed that this queen overproduction is the result of self-determination over caste fate, whereby females enhance their own inclusive fitness by developing into a queen (Bourke \& Ratnieks 1999; Ratnieks 2001), which leads to up to $20 \%$ of all females developing into queens (Ratnieks \& Wenseleers 2008). In swarm-founding species such as Melipona bees, producing this large number of queens is not beneficial to the colony as it would be in species with solitary foundresses. This is because the ability to found colonies by swarming is limited by the number of workers, and females that develop into queens will compromise the production of new workers (Michener 1974; Ratnieks 2001). Indeed, evidence for queens being produced in excess of colony needs is provided by the fact that workers kill many of the newly emerged gynes soon after they eclose from their cells (Silva et al. 1972; Koedam et al. 1995; Wenseleers et al. 2004) and that they chase many of the gynes out of the colony (Sommeijer et al. 2003b; Sommeijer \& De Bruijn 2003). For example, in M. favosa, it has been demonstrated that $43 \%$ of all gynes are killed by the workers and that the remaining $57 \%$ are chased out of the colony by the workers (Sommeijer et al. 2003b). The fact that opportunities for Melipona queens to supersede their mother queen or head a new daughter swarm are so limited means that their queens will also be strongly selected to try to seek alternative strategies to reproduce, such as taking over other colonies (Sommeijer et al. 2003a; Wenseleers et al. 2011).

In this study we assessed the behavioural strategies employed by $M$. scutellaris queens when infiltrating (unrelated) colonies, by tracking their movements using radio frequency identification (RFID) tags. To discern whether there is a preference for queens to attempt to infiltrate colonies without a queen, as was suggested to occur by the earlier study of Wenseleers et al. (2011), we monitored four queenright and four queenless colonies for the occurrence of queen infiltration events. Furthermore, since a reduced guarding efficiency in queenless hives might be an important explanatory factor for the observed preference, we also investigated a possible link between guarding efficiency and the timing and pattern of attempted queen infiltration.

\section{METHODS}

\section{Incidence of Queen Parasitism}

To assess the incidence of intraspecific queen parasitism in M. scutellaris, we monitored eight colonies in the Laboratory of Ecology and Behaviour of Social Insects at the University of São Paulo (Ribeirão Preto city, Brazil) in February and March 2012. Permission to conduct our research was granted by the Brazilian Ministry of Environment under permit 12BR008955/DF. Melipona scutellaris is a tree dweller that nests in tree hollows and occurs naturally in the north and northeast of Brazil (Alves et al. 2012). In our study, colonies were maintained in free-foraging wooden nestboxes which were covered with glass lids to allow observations and were placed inside a laboratory $60 \mathrm{~cm}$ apart. Natural Melipona populations have densities of 1-4 colonies/ha (Antonini \& Martins 2003), although it is not uncommon to find several nests in the same tree within a few metres from each other (Antonini \& Martins 2003; Alves et al. 2005). However, the São Paulo region is not within the natural range of this species, being ca. $1000 \mathrm{~km}$ south of the southernmost edge of its range (Camargo \& Pedro 2007; Alves et al. 2012). We therefore argue that the gynes did not have access to more colonies than in natural populations, and that our data are not inflated by a high colony density in the apiary. At the start of the experiment, we removed the mother queens in four of the colonies, whereas the remaining four were kept queenright. There were two small and two large queenless colonies, and two small and two large queenright colonies. The colony size was estimated based on the number of food pots and estimated number of workers present; a colony was labelled as small when there were few food pots and 200-500 workers present, while large colonies contained several food pots and more than a thousand workers. In the queenright test colonies, the mother queen was marked with a coloured bee tag, so that any queen take-over event could rapidly be detected. In all test colonies, we removed old brood combs regularly, which were then placed inside a wooden box in an incubator $\left(28^{\circ} \mathrm{C}\right)$, allowing us to collect and individually mark all newly emerged queens with RFID tags (mic3 Transponder 64RO bee tags, Microsensys Gmbh, Erfurt, Germany), which were glued onto the gynes' thoraces with a drop of Araldite glue (Fig. 1a). After marking, the glue was allowed to dry for at least 10 min while the bees were kept in a petri dish. Subsequently, the tagged gynes and newly emerged workers were distributed randomly over our eight test colonies, with equal numbers being added daily to each colony. The mixing of alien and natal bees for introduction is assumed not to affect the experiment, since all introduced bees were newly emerged and therefore had not yet acquired a colony-specific odour (Inoue et al. 1999; Breed et al. 2004). To gather information on the timing of the queens' entries and departures, we used iID MAJA readers (Microsensys Gmbh, Erfurt, Germany) that were placed at the entrance of each of the eight colonies and connected to an iID host computer. In (a)

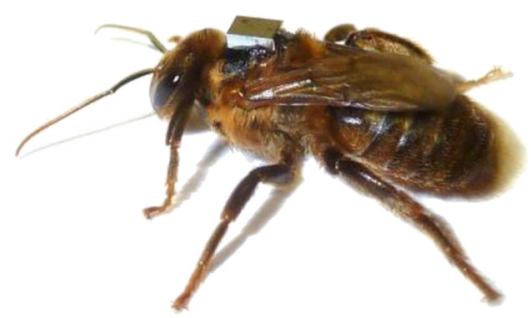

(b)

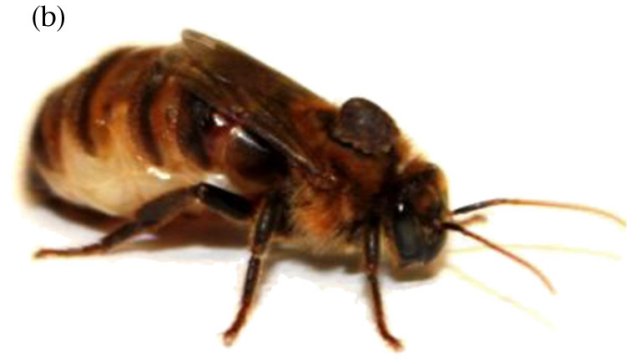

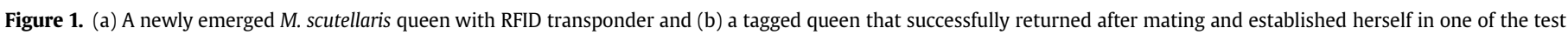
colonies. 
queenless colonies, we rapidly removed queens if they successfully established themselves, thereby keeping these colonies queenless throughout the experiment. Queens were considered to have successfully established themselves when we found a queen with an enlarged abdomen inside the colony (Fig. 1b). Queens that were found inside the colonies but that were only slightly physogastric were freeze-killed and dissected to determine whether they were indeed inseminated. In some cases, untagged queens successfully took over colonies. These queens could have lost their RFID tags or could have originated from other colonies in the apiary. To determine their origin (natal or alien), such queens were freeze-killed and genotyped as described previously by Wenseleers et al. (2011).

The proportion of tagged virgin queens leaving queenless versus queenright colonies and the queens' preference for entering colonies of a certain size or queenless/queenright state were tested with a chi-square test, a Fisher's exact test and an exact binomial test, respectively. To assess whether the times at which queens entered colonies were more clustered than expected by chance, we used a Monte Carlo simulation. For this, $P$ values were obtained using a parametric bootstrapping technique in which we simulated 10000 repetitions of the observed number of entry times over a period of $12 \mathrm{~h}$ under a uniform distribution, and test statistics were based on the time difference between the minimum and maximum observed entry time.

\section{Guarding Efficiency}

To quantify the guarding efficiency in queenless and queenright colonies of $M$. scutellaris, we carried out behavioural observations in three queenless and three queenright colonies in June 2012. Plastic boxes with a transparent glass lid and entrance holes were mounted in front of the colony entrances 2 weeks prior to the actual behavioural observations. Each experimental trial was based on the introduction of one nestmate and one non-nestmate worker inside the observation box, in random order, with the observer blind to the origin of the introduced worker. Introducing newly mated natal and alien queens instead of workers might be a more suitable approach to assess guards' aggression towards parasitic queens accurately, but this was impractical because of the limited number of queens returning after mating flights. By using nestmate and non-nestmate workers, however, we could still accurately assess the guarding efficiency of colonies throughout the day. The nonnestmate workers were collected in the apiary in colonies other than the test colonies. Prior to the trial, the introduced workers were chilled in a cooling box to immobilize them slightly and prevent them from flying off. After introduction of the nestmates or non-nestmates, the interactions with the entrance guards were observed and noted for $3 \mathrm{~min}$. An interaction was defined as aggressive when the introduced worker was severely attacked (including biting, grappling and dragging) for longer than $2 \mathrm{~s}$. Behavioural trials were carried out over a period of 6 days from the early morning until sunset (from 0700 to 1900 hours GMT-3), with two experimental trials per hour. To minimize the additive effect of repeated introductions on the guards' aggressive behaviour, we removed introduced bees after they were continuously attacked (for longer than $20 \mathrm{~s}$ ), and we limited the number of trials per hour to two. Removed bees were freeze-killed after the experimental trial. Guarding efficiency, measured by the mean number of interacting guards and the frequency of aggressive interactions by the host workers, was compared using Poisson generalized linear mixed models (GLMMs), in which colony was coded as a random factor and time of day as a covariate. Acceptance rates were analysed with binomial GLMMs, in which colony was again coded as a random factor and time of day as a covariate. For these GLMMs, a Wald test was used to test the significance levels for the fixed effects. All statistical tests were carried out in $\mathrm{R}$ version 2.15 .2 (The $\mathrm{R}$ Foundation for Statistical Computing, Vienna, Austria, http:// www.r-project.org), using the package lme4 and function glmer for the GLMMs.

\section{RESULTS}

During the timeframe of our study, five of 520 tagged virgin queens were found to return successfully to the test colonies after mating. In addition, five untagged queens were found to have successfully established themselves in our test colonies. In one case, one tagged queen tried to penetrate two different colonies, and succeeded in doing so during her last attempt (Table 1). The number of tagged virgin queens leaving the colony was relatively low at just over $45 \%$ on average. This may be explained by workers killing gynes inside the colonies after introduction, by gynes losing their RFID tags inside the colonies and by possible misreads by the RFID readers. Tagged virgin queens, however, were equally likely to leave queenless and queenright colonies $(P>0.2)$. Queens that successfully returned to the test colonies spent on average $12.15 \pm 2.85$ days (mean \pm SD) inside the test colonies before leaving, and, after leaving, returned within an average of $19.9 \pm 7.9$ h (mean \pm SD).

\section{Incidence of Queen Parasitism}

Our data confirm that alien queen take-overs are common in M. scutellaris, since $37.5 \%$ (three of eight) of the successful queen supersedure events were undertaken by unrelated queens (Table 1). Furthermore, mated queens only attempted to take over queenless colonies, whereas there were no take-overs (successful or attempted) in queenright colonies (Table 1). Our results therefore support the theory that newly mated queens selectively seek out colonies without a queen (exact binomial test: two-tailed $P=0.0005$ ). Mated queens did not show a significant preference for colonies of a certain size (large or small, Fisher's exact test: twotailed $P=0.21$ ), which demonstrates that parasitic queens were no more likely to take over small colonies.

All registered queen take-over attempts took place in the evening around sunset or later (Table 1 ). The data points were significantly more clustered than expected by chance (Monte Carlo test: $N=6, P=0.006$ ). This test assumed a uniform distribution of entry times over the typical $12 \mathrm{~h}$ of daylight when bees are observed to be

Table 1

Summary of Melipona scutellaris queens that attempted or succeeded in entering the study colonies

\begin{tabular}{llllllll}
\hline Queen & & $\begin{array}{l}\text { Target } \\
\text { colony }\end{array}$ & $\begin{array}{l}\text { Colony } \\
\text { ID }\end{array}$ & $\begin{array}{l}\text { Queen's } \\
\text { origin }\end{array}$ & Attempts & $\begin{array}{l}\text { Time of } \\
\text { infiltration }\end{array}$ & Sunset \\
\hline Tagged & 1 & Queenless & S1 & Natal & Successful & 1804 & 1848 \\
& 2 & Queenless & S1 & Natal & Failed & 1935 & 1844 \\
& 3 & Queenless & S2 & Natal & Failed & 2031 & 1843 \\
& & Queenless & S2 & Natal & Failed & 1747 & 1842 \\
& & Queenless & L1 & Alien & Successful & $?$ & \\
& 4 & Queenless & S1 & Natal & Failed & 1721 & 1836 \\
& 5 & Queenless & L1 & Alien & Successful & 1804 & 1826 \\
& 1 & Queenless & S1 & Natal & Successful & $?$ & \\
& 2 & Queenless & S1 & Natal & Successful & $?$ & \\
& 3 & Queenless & L1 & Natal & Successful & $?$ & \\
& 4 & Queenless & L1 & Natal & Successful & $?$ & \\
& 5 & Queenless & S1 & Alien & Successful & $?$ & \\
\hline
\end{tabular}

The colony ID provides information on the size of the target colonies: small is indicated with an ' $S$ ', and large with an ' $L$ '. Note that one attempt, the third attempt by queen 3 , was not registered owing to a misreading. Queen 3 attempted to enter colony S2 twice, on 2 consecutive days. As a reference point, the time of sunset is given for all registered entries. 
active. The assumption of $12 \mathrm{~h}$ might seem arbitrary, but if a longer time window (e.g. $24 \mathrm{~h}$ ) were used, the $P$ value would only be smaller, indicating that this time window is conservative. In addition, a nonuniform distribution for entry times that matched empirically observed foraging activity could be assumed. However, such a distribution would be skewed towards the hours from morning until early afternoon when bees are maximally active (Roubik \& Buchmann 1984; Pierrot \& Schlindwein 2003) and would thus only further increase the significance of this result.

\section{Guarding Efficiency}

The preference of mated queens to take over queenless colonies was not a result of a reduced guarding efficiency in queenless colonies, since the number of interacting guards per encounter and the number of aggressive interactions per encounter were not significantly different for queenright and queenless colonies (Poisson GLMM: $N=720, P=0.57$ and $P=0.91$, respectively). The time of day had a significant effect on the guarding efficiency of a colony, with the number of interacting guards and the number of aggressive interactions per encounter significantly decreasing throughout the day (Poisson GLMM: $N=720$, both $P<0.0001$ ) and the acceptance rate of introduced bees increasing towards the end of the day (binomial GLMM: $N=720, P=0.014$ ). Around the time of sunset the guarding efficiency was at its lowest (Fig. 2).
Overall, guards could effectively distinguish nestmate from nonnestmate workers, with $65.5 \%$ of non-nestmates but only $7.4 \%$ of nestmates being attacked. Indeed, our results show that the number of aggressive interactions with non-nestmates was significantly higher than with their nestmates (Poisson GLMM: $N=720$, $P<0.0001$ ) and that the number of interacting guards was significantly higher in interactions with non-nestmates than with nestmates (Poisson GLMM: $N=720, P<0.0001$ ). These results also translate into a lower acceptance rate for non-nestmates (28\%) than nestmates (72\%; binomial GLMM: $N=720, P<0.0001$ ).

\section{DISCUSSION}

Our study confirms that queen parasitism is common in the stingless bee $M$. scutellaris, with $37.5 \%$ of the successful take-overs being undertaken by unrelated queens, which is consistent with an earlier genetic study on queen parasitism in this species (Wenseleers et al. 2011). The frequent occurrence of queen parasitism implies that this alternative reproductive strategy might be employed relatively often by lone nest-searching queens. In addition, we demonstrate that $M$. scutellaris queens can selectively seek out colonies without a queen to reproduce in and show that the observed preference to enter queenless colonies is not simply the result of a trial-and-error process. If they used trial and error, newly mated queens would just attempt to try to enter any colony,
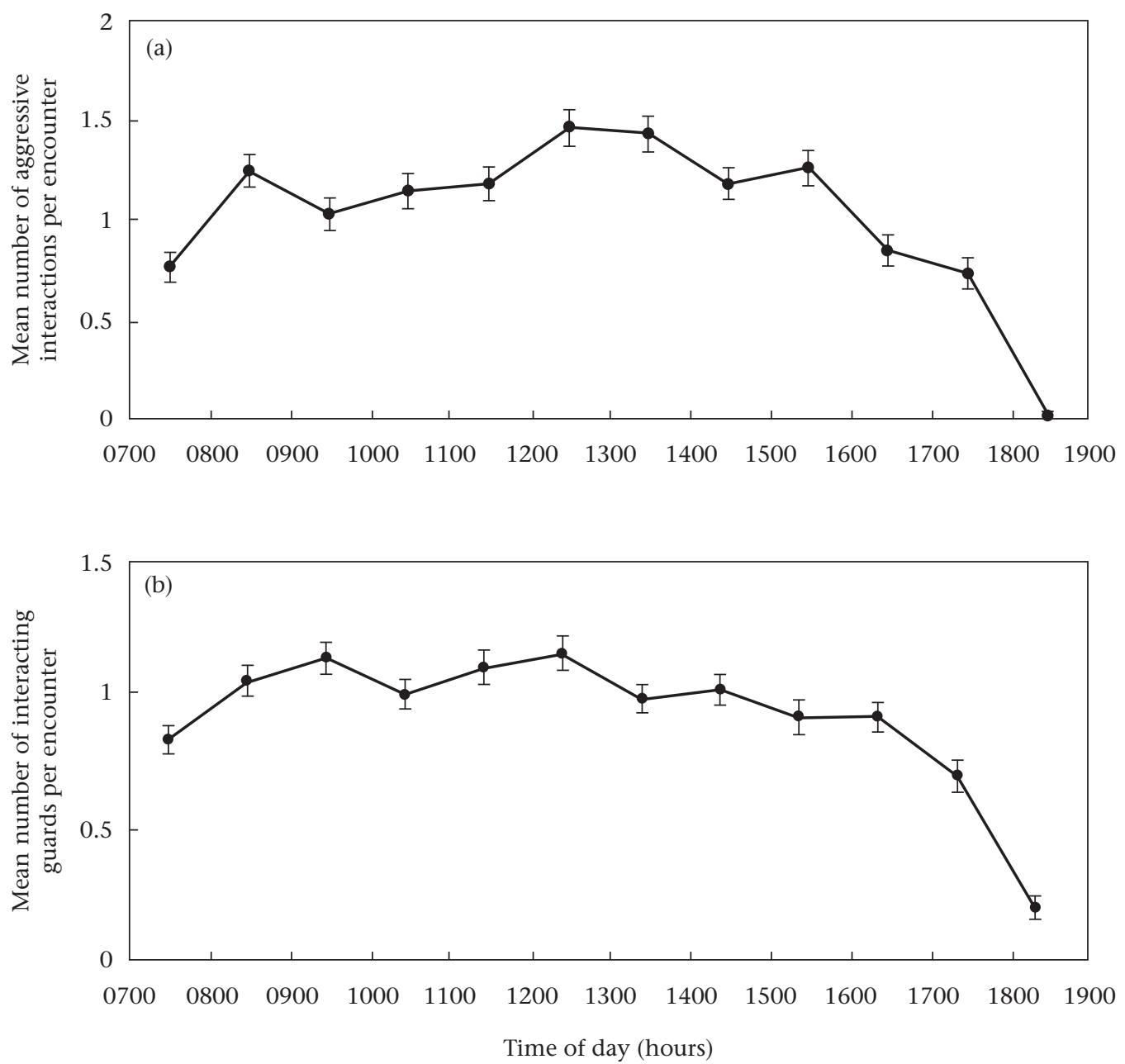

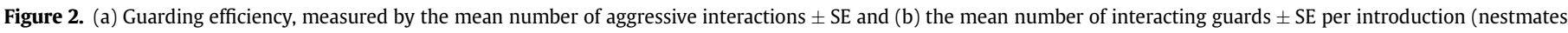
and non-nestmates) as a function of the time of day (GMT-3). During these experiments sunset occurred around 1737. 
including queenright ones, which was never observed in this study. Hence, our results support the hypothesis that queens prefer to infiltrate queenless colonies. A similar preference for invading queenless colonies was found in the honeybee: swarms of Africanized honeybees prefer to invade queenless European honeybee colonies over queenright colonies (Vergara et al. 1993). Which cues alien queens use to detect queenless colonies remains unknown. In stingless bees, queenless colonies tend to be more restless and irritable compared to colonies that are headed by a queen (Hoffmann 1961; D. Alves, personal observation), which might be explained by the absence of queen pheromones that are thought to have a stabilizing effect on colony behaviour (Velthuis 1977). Hence, cues such as restlessness or even the absence of queen-specific pheromones might be used by nest-seeking queens to decide whether or not to enter a colony. Furthermore, we have shown that the guarding system of $M$. scutellaris is highly efficient, and that it is equally efficient in queenless and queenright colonies. This strengthens our hypothesis that the observed preference for queens to take over queenless colonies is not due to higher rejection rates in queenright colonies. Similar results were found in A. mellifera capensis honeybees, in which the rejection rate of alien workers was similar in queenless and queenright colonies (Beekman et al. 2002), and in A. mellifera ligustica, in which queenless colonies even showed a slightly higher vigilance towards alien workers than guards of queenright colonies (Chapman et al. 2010). By contrast, queenless colonies of the Asiatic honeybee were recently shown to be more accepting of introduced workers, compared to queenright colonies (Holmes et al. 2013).

We also found that newly mated queens attempted to enter colonies late in the evening when guarding efficiency was at its lowest, presumably to have a higher chance of avoiding detection by the guards. Guards play a major role in rejecting intruders (Bell et al. 1974), which means that passing the guards is probably the most hazardous part of infiltrating another colony. Indeed, it has been shown in another stingless bee, Hypotrigona gribodoi, that the introduction of non-nestmates directly inside a nest does not elicit aggression by the workers, while placing them at the nest entrance resulted in attacks by the entrance guards (Kirchner \& Friebe 1999). A similar pattern seems to apply to M. scutellaris, since merely $14 \%$ of the non-nestmates were attacked when they were introduced directly into the nest (Breed \& Page 1991), while our results showed that guards attacked almost $66 \%$ of all non-nestmates when they were introduced near the nest entrance. The fact that guarding efficiency decreased during the day, and was at its lowest around the time of sunset (Fig. 2) is consistent with Melipona foraging bees being most active from dawn to dusk (Biesmeijer \& Tóth 1998), with a peak in activity being observed from the early morning until the early afternoon (Roubik \& Buchmann 1984; Pierrot \& Schlindwein 2003). Presumably, efficient guarding is needed mostly during these hours of peak activity to keep robbing bees out of the colony, and our results suggest that queens also use this temporal effect to their benefit to infiltrate unrelated colonies.

A particularly intriguing finding of our study is that two mated queens attempted to enter the study colonies well past sunset (Table 1), when it was already dark. Moonlight has been shown to play an important role for navigation in a few bee species (e.g. Dyer 1985; Warrant 2008), but nocturnal flights have never been observed in stingless bees. Our RFID data showed a minority of gynes (2\%) leaving their colonies at night, which could be the result of workers chasing them out, as is observed in M. favosa (Sommeijer \& De Bruijn 2003), or it could be an indication of their ability to fly at night. It seems most plausible, however, that queens search for suitable colonies during the day, because they presumably use the celestial position of the sun to navigate, as honeybees do (Kalmus 1956; Menzel et al. 1990). Indeed, this appears to be the case for the workers, which forage exclusively during the day (Roubik \& Buchmann 1984; Biesmeijer \& Tóth 1998; Pierrot \& Schlindwein 2003). Hence, we suggest that it is likely that queens locate a queenless colony when there is still enough daylight, and wait near the targeted colony to enter later.

A key question that remains is why workers accept unrelated queens, since rearing unrelated brood would not provide them with any inclusive fitness benefits. The most plausible explanation is one that has already been proposed to explain the persistence of cuckoo brood parasitism: it has been suggested that host defence against brood parasitism bears a significant cost when hosts 'misfire' and reject their own eggs (Marchetti 1992). In the case of queen parasitism, a strong defence against infiltrating queens can be selectively disadvantageous when workers have a significant chance of rejecting a natal queen, which could have detrimental consequences for the colony's longevity. Hence, a more relaxed defence system could be more advantageous, even if alien queens are accepted occasionally. In addition, the phenomenon of queen parasitism could be explained by alternative mechanisms that are not necessarily mutually exclusive. One explanation is that workers accept unrelated queens as a strategy of 'making the best of a bad situation' when there are no daughter queens to replace the mother queen after she has died, as this would still enable the workers to keep on producing their own males several months after a new queen has been established (Alves et al. 2009). In this way, they would still obtain some fitness benefits, even if they accept an unrelated queen (Alves et al. 2009). Indeed, our results demonstrate that only a small percentage of the tagged queens (2\%) actually returned after leaving the test colonies, which might indicate that the chances of surviving on mating flights are relatively low, as has also been reported for other stingless bee species (Roubik 2006). This, together with the fact that the life expectancy of queens is relatively short (ca. 175 days in M. scutellaris, Wenseleers et al. 2011), makes the 'making the best of a bad situation' explanation plausible. Another explanation is that mated queens could force the workers into accepting them through the use of particular pheromones. The phenomenon whereby the queen chemically manipulates workers to act against their own best interests has been dubbed the 'queen control hypothesis' by Keller \& Nonacs (1993). Although this theory has received a vast amount of criticism when applied to the evolution of worker sterility in social insects (Seeley 1985; Keller \& Nonacs 1993; D'Ettorre et al. 2004; Holman et al. 2010), it might well apply in the context of intraspecific queen parasitism. This is because in a parasite-host system, the parasite can exploit an honest signalling system in a dishonest manner (Heinze \& d'Ettorre 2009). In the case of intraspecific queen parasitism, for example, queens could produce pheromones that honestly signal fertility but at the same time cause workers to act against their own best interests by obeying this signal and accepting an unrelated queen. The fact that fecund queens can easily be exchanged between unrelated colonies (Monteiro \& Kerr 1990; Sommeijer et al. 2003a) could be consistent with such a form of queen pheromonal control. Additionally, the possibility of a queen being rejected when taking over an unrelated colony could be inherently low, because workers are overly attracted to queens in general. Strong queen attraction is suggested by studies demonstrating the merging of unrelated queenright and queenless colonies (Wongvilas et al. 2010; Kronauer et al. 2010). Such mergers have even been reported between colonies of different species, illustrating the potency of queen attraction as there are no inclusive fitness benefits (Wongvilas et al. 2010).

In interspecific host-parasite systems within the social Hymenoptera, the focus has mainly been on the chemical aspects of the infiltration strategies, while behavioural aspects have often been more neglected (e.g. Howard et al. 1980; Allies et al. 1986; Lenoir 
et al. 2001; Johnson et al. 2005; Bagnères \& Lorenzi 2010; Uboni et al. 2012). In this study, we have presented the first indications of the existence of a behavioural strategy based on timing to infiltrate colonies, whereby 'parasite queens' attempt to infiltrate host colonies when guarding efficiency is at its lowest. An interesting direction for future research would be to determine the generality of this phenomenon in other taxa as well as in interspecific hostparasite systems.

\section{Acknowledgments}

This work was supported financially by the FWO-Flanders, FAPESP (grant numbers 2010/19717-4 to D.A.A., 2010/10027-5 to F.S.N. and 2011/21084-2 to T.W.), the Research Center on Biodiversity and Computing (BioComp) of the Universidade de São Paulo (USP), supported by the USP Provost's Office for Research, and the Royal Belgian Entomological Society (poster prize to A.V.O.). We are grateful to Edgar Duéñez-Guzmán for his helpful comments on the manuscript. We appreciate the useful comments of two anonymous referees.

\section{References}

Allies, A. B., Bourke, A. F. \& Franks, N. R. 1986. Propaganda substances in the cuckoo ant Leptothorax kutteri and the slave-maker Harpagoxenus sublaevis. Journal of Chemical Ecology, 12, 1285-1293.

Alves, R. M., Carvalho, C. A. \& Souza, B. A. 2005. Ninhos de Melipona scutellaris L. em coqueiros na regiao do litoral Norte e metropolitana no Estado da Bahia. Mensagem Doce, 83, 3-5.

Alves, D. A., Imperatriz-Fonseca, V. L., Francoy, T. M., Santos-Filho, P. S., Nogueira-Neto, P., Billen, J. \& Wenseleers, T. 2009. The queen is dead: long live the workers: intraspecific parasitism by workers in the stingless bee Melipona scutellaris. Molecular Ecology, 18, 4102-4111.

Alves, R. M., Carvalho, C. A., Souza, B. A. \& Santos, W. S. 2012. Areas of natural occurrence of Melipona scutellaris Latreille, 1811 (Hymenoptera: Apidae) in the State of Bahia, Brazil. Anais da Academia Brasileira de Ciências, 84, 679-688.

Antonini, Y. \& Martins, R. P. 2003. The value of a tree species (Caryocar brasiliense) for a stingless bee Melipona quadrifasciata quadrifasciata. Journal of Insect Conservation, 7, 167-174.

Bagnères, A.-G. \& Lorenzi, M. 2010. Chemical deception/mimicry using cuticular hydrocarbons. In: Insect Hydrocarbons: Biology, Biochemistry and Chemical Ecology (Ed. by G. J. Blomquist \& A. G. Bagnères), pp. 282-324. Cambridge: Cambridge University Press.

Beekman, M., Wossler, T. C., Martin, S. J. \& Ratnieks, F. L. W. 2002. Parasitic Cape honey bee workers (Apis mellifera capensis) are not given differential treatment by African guards (A. m. scutellata). Insectes Sociaux, 49, 216-220.

Bell, W. J., Breed, M. D., Richards, K. W. \& Michener, C. D. 1974. Social, stimulatory and motivational factors involved in intraspecific nest defense of a primitively eusocial halictine bee. Journal of Comparative Physiology A: Neuroethology, Sensory, Neural, and Behavioral Physiology, 93, 173-181.

Biesmeijer, J. C. \& Tóth, E. 1998. Individual foraging, activity level and longevity in the stingless bee Melipona beecheii in Costa Rica (Hymenoptera, Apidae, Meliponinae). Insectes Sociaux, 45, 427-443.

Birmingham, A. L., Hoover, S. E., Winston, M. L. \& Ydenberg, R. C. 2004. Drifting bumble bee (Hymenoptera: Apidae) workers in commercial greenhouses may be social parasites. Canadian Journal of Zoology, 82, 1843-1853.

Bourke, A. F. G. \& Ratnieks, F. L. W. 1999. Kin conflict over caste determination in social Hymenoptera. Behavioral Ecology and Sociobiology, 46, 287-297.

Breed, M. D. 1983. Nestmate recognition in honey bees. Animal Behaviour, 31, 86-91.

Breed, M. D. \& Page, R. E. 1991. Intraspecific and interspecific nestmate recognition in Melipona workers (Hymenoptera, Apidae). Journal of Insect Behavior, 4, 463469

Breed, M. D., Butler, L. \& Stiller, T. M. 1985. Kin discrimination by worker honey bees in genetically mixed groups. Proceedings of the National Academy of Sciences, U.S.A., 82, 3058-3061.

Breed, M. D., Perry, S. \& Bjostad, L. B. 2004. Testing the blank slate hypothesis: why honey bee colonies accept young bees. Insectes Sociaux, 5, 12-16.

Buchwald, R. \& Breed, M. D. 2005. Nestmate recognition cues in a stingless bee, Trigona fulviventris. Animal Behaviour, 70, 1331-1337.

Camargo, J. M. \& Pedro, S. R. 2007. Meliponini Lepeletier, 1836. In: Catalogue of Bees (Hymenoptera, Apoidea) in the Neotropical Region (Ed. by J. S. Moure, D. Urban \& G. A. R. Melo), pp. 272-578. Curitiba: Sociedade Brasileira de Entomologia.

Chapman, N. C., Nanork, P., Gloag, R., Wattanachaiyingcharoen, W. Beekman, M. \& Oldroyd, B. 2009. Queenless colonies of the Asian red dwarf honey bee (Apis florea) are infiltrated by workers from other queenless colonies. Behavioral Ecology, 20, 817-820.
Chapman, N. C., Beekman, M. \& Oldroyd, B. P. 2010. Worker reproductive parasitism and drift in the western honeybee Apis mellifera. Behavioral Ecology and Sociobiology, 64, 419-427.

D'Ettorre, P., Heinze, J., Schulz, C., Francke, W. \& Ayasse, M. 2004. Does she smell like a queen? Chemoreception of a cuticular hydrocarbon signal in the ant Pachycondyla inversa. Journal of Experimental Biology (Cambridge), 207, 1085-1091.

Downs, S. G. \& Ratnieks, F. L. W. 2000. Adaptive shifts in honey bee (Apis mellifera L.) guarding behavior support predictions of the acceptance threshold model. Behavioral Ecology, 11, 326-333.

Dyer, F. C. 1985 . Nocturnal orientation by the Asian honey bee, Apis dorsata. Animal Behaviour, 33, 769-774.

Gamboa, G. J. 1986. The evolution and ontogeny of nestmate recognition in social wasps. Annual Review of Entomology, 31, 431-454.

Heinze, J. \& d'Ettorre, P. 2009. Honest and dishonest communication in socia Hymenoptera. Journal of Experimental Biology, 212, 1775-1779.

Hoffmann, I. 1961. Über die Arbeitsteilung in weiselrichtigen und weisellosen Kleinvölkern der Honigbiene. Zeitschrift für Bienenforschung, 5, 267-279.

Holman, L., Jørgensen, C. G., Nielsen, J. \& d'Ettorre, P. 2010. Identification of an ant queen pheromone regulating worker sterility. Proceedings of the Royal Society $B$ 277, 3793-3800.

Holmes, M., Tan, K., Wang, Z., Oldroyd, B. \& Beekman, M. 2013. Honeybee (Apis cerana) guards do not discriminate between robbers and reproductive parasites. Insectes Sociaux, 60, 265-271.

Howard, R. W., McDaniel, C. A. \& Blomquist, G. J. 1980. Chemical mimicry as an integrating mechanism: cuticular hydrocarbons of a termitophile and its host. Science, 210, 431-433.

Inoue, T., Roubik, D. \& Suka, T. 1999. Nestmate recognition in the stingless bee Melipona panamica (Apidae, Meliponini). Insectes Sociaux, 46, 208-218.

Johnson, C. A., Topoff, H., Vander Meer, R. K. \& Lavine, B. 2005. Do these eggs smell funny to you?: an experimental study of egg discrimination by hosts of the social parasite Polyergus breviceps (Hymenoptera: Formicidae). Behaviora Ecology and Sociobiology, 57, 245-255.

Jones, S. M., van Zweden, J. S., Grüter, C., Menezes, C., Alves, D. A., Nunes-Silva, P. Czaczkes, T., Imperatriz-Fonseca, V. L. \& Ratnieks, F. L. 2012. The role of wax and resin in the nestmate recognition system of a stingless bee, Tetragonisca angustula. Behavioral Ecology and Sociobiology, 66, 1-12.

Kalmus, H. 1956. Sun navigation of Apis mellifica L. in the southern hemisphere Journal of Experimental Biology, 33, 554-565.

Keller, L. \& Nonacs, P. 1993. The role of queen pheromones in social insects: queen control or queen signal? Animal Behaviour, 45, 787-794.

Kerr, W. E. 1950. Genetic determination of castes in the genus Melipona. Genetics, 35, 143-152.

Kirchner, W.H. \& Friebe, R. 1999. Nestmate discrimination in the African stingless bee Hypotrigona gribodoi Magretti (Hymenoptera: Apidae). Apidologie, 30, 293-298.

Koedam, D., Monge, I. A. \& Sommeijer, M. J. 1995. Social interactions of gynes and their longevity in queenright colonies of Melipona favosa (Apidae: Meliponinae). Netherlands Journal of Zoology, 45, 480-494.

Kronauer, D. J., Schöning, C., d'Ettorre, P. \& Boomsma, J. J. 2010. Colony fusion and worker reproduction after queen loss in army ants. Proceedings of the Royal Society B, 277, 755-763.

Lenoir, A., d'Ettorre, P., Errard, C. \& Hefetz, A. 2001. Chemical ecology and social parasitism in ants. Annual Review of Entomology, 46, 573-599.

Lopez-Vaamonde, C., Koning, J. W., Brown, R. M., Jordan, W. C. \& Bourke, A. F. G. 2004. Social parasitism by male-producing reproductive workers in a eusocial insect. Nature, 430, 557-560.

Marchetti, K. 1992. Costs to host defence and the persistence of parasitic cuckoos Proceedings of the Royal Society B, 248, 41-45.

Menzel, R., Chittka, L., Eichmüller, S., Geiger, K., Peitsch, D. \& Knoll, P. 1990. Dominance of celestial cues over landmarks disproves map-like orientation in honey bees. Zeitschrift für Naturforschung, 45, 723-726.

Michener, C. D. 1974. The Social Behavior of the Bees. Cambridge, Massachusetts: Harvard University Press.

Monteiro, C. \& Kerr, W. E. 1990. Experimental exchange of queens between colonies of Melipona compressipes (Apidae, Meliponini). Revista Brasileira de Biologia, 50, 975-981.

Nanork, P., Paar, J., Chapman, N. C., Wongsiri, S. \& Oldroyd, B. P. 2005. Asian honeybees parasitize the future dead. Nature, 437, 829.

Nanork, P., Chapman, N. C., Wongsiri, S., Lim, J., Gloag, R. S. \& Oldroyd, B. P. 2007 Social parasitism by workers in queenless and queenright Apis cerana colonies. Molecular Ecology, 16, 1107-1114.

Nascimento, D. \& Nascimento, F. 2012. Acceptance threshold hypothesis is supported by chemical similarity of cuticular hydrocarbons in a stingless bee, Melipona asilvai. Journal of Chemical Ecology, 38, 1432-1440.

Nash, D. R. \& Boomsma, J. J. 2008. Communication between hosts and socia parasites. In: Sociobiology of Communication: an Interdisciplinary Approach (Ed. by P. d'Ettorre \& D. P. Hughes), pp. 55-79. Oxford: Oxford University Press.

Pierrot, L. M. \& Schlindwein, C. 2003. Variation in daily flight activity and foraging patterns in colonies of uruçu-Melipona scutellaris Latreille (Apidae, Meliponini). Revista Brasileira de Zoologia, 20, 565-571.

Ratnieks, F. L. W. 2001. Heirs and spares: caste conflict and excess queen production in Melipona bees. Behavioral Ecology and Sociobiology, 50, 467-473.

Ratnieks, F. L. W. \& Wenseleers, T. 2008. Altruism in insect societies and beyond: voluntary or enforced? Trends in Ecology \& Evolution, 23, 45-52. 
Roubik, D. W. 2006. Stingless bee nesting biology. Apidologie, 37, 124-143.

Roubik, D. W. \& Buchmann, S. L. 1984. Nectar selection by Melipona and Apis mellifera (Hymenoptera, Apidae) and the ecology of nectar intake by bee colonies in a tropical forest. Oecologia, 61, 1-10.

Santos-Filho, P. d. S., Alves, D. d. A., Eterovic, A., Imperatriz-Fonseca, V. L. \& Kleinert, A. d. M. P. 2006. Numerical investment in sex and caste by stingless bees (Apidae: Meliponini): a comparative analysis. Apidologie, 37, 207-221.

Seeley, T. D. 1985. Honeybee Ecology. A Study of Adaptation in Social Life. Princeton, New Jersey: Princeton University Press.

Silva, D. L. N., Zucchi, R. \& Kerr, W. E. 1972. Biological and behavioural aspects of the reproduction in some species of Melipona (Hymenoptera, Apidae, Meliponinae). Animal Behaviour, 20, 123-132.

Singer, T. L. \& Espelie, K. E. 1992. Social wasps use nest paper hydrocarbons for nestmate recognition. Animal Behaviour, 44, 63-68.

Sommeijer, M. J. \& De Bruijn, L. L. 2003. Why do workers of Melipona favosa chase their sister-gynes out of the nest? Proceedings of the Section Experimental and Applied Entomology: Netherlands Entomological Society, 12, 45-48.

Sommeijer, M. J., De Bruijn, L. L. M. \& Meeuwsen, F. 2003a. Reproductive behaviour of stingless bees: solitary gynes of Melipona favosa (Hymenoptera: Apidae, Meliponini) can penetrate existing nests. Entomologische Berichten, 63 31-35.

Sommeijer, M. J., De Bruijn, L. L. M., Meeuwsen, F. \& Slaa, E. J. 2003b. Reproductive behaviour of stingless bees: nest departures of non-accepted gynes and nuptial flights in Melipona favosa (Hymenoptera: Apidae, Meliponini). Entomologische Berichten, 63, 7-13.

Stuart, R. J. 1988. Collective cues as a basis for nestmate recognition in polygynous leptothoracine ants. Proceedings of the National Academy of Sciences, U.S.A., 85 $4572-4575$.
Takahashi, J., Martin, S. J., Ono, M. \& Shimizu, I. 2010. Male production by nonnatal workers in the bumblebee, Bombus deuteronymus (Hymenoptera: Apidae). Journal of Ethology, 28, 61-66.

Uboni, A., Bagnères, A.-G., Christidès, J.-P. \& Cristina Lorenzi, M. 2012. Cleptoparasites, social parasites and a common host: chemical insignificance for visiting host nests, chemical mimicry for living in. Journal of Insect Physiology, 58, 1259-1264.

van Zweden, J. S. \& d'Ettorre, P. 2010. Nestmate recognition in social insects and the role of hydrocarbons. Insect Hydrocarbons: Biology, Biochemistry and Chemical Ecology, 11, 222-243.

Velthuis, H. 1977. The evolution of honeybee queen pheromones. Proceedings of the VIII Congress of the IUSSI, 220-222.

Vergara, C., Dietz, A. \& Leon, A. d 1993. Female parasitism of European honey bees by Africanized honey bee swarms in Mexico. Journal of Apicultural Research, 32, 34-40.

Warrant, E. J. 2008. Seeing in the dark: vision and visual behaviour in nocturnal bees and wasps. Journal of Experimental Biology, 211, 1737-1746.

Wenseleers, T. \& Ratnieks, F. L. W. 2004. Tragedy of the commons in Melipona bees. Proceedings of the Royal Society B, 271, S310-S312.

Wenseleers, T., Hart, A. G., Ratnieks, F. L. W. \& Quezada-Euan, J. J. G. 2004. Queen execution and caste conflict in the stingless bee Melipona beecheii. Ethology, 110, 725-736.

Wenseleers, T., Alves, D. A., Francoy, T. M., Billen, J. \& Imperatriz-Fonseca, V. L. 2011. Intraspecific queen parasitism in a highly eusocial bee. Biology Letters, $\mathbf{7}$, $173-176$.

Wilson, E. O. 1971. The Insect Societies. Cambridge, Massachusetts: Harvard University Press.

Wongvilas, S., Deowanish, S., Lim, J., Xie, V., Griffith, O. \& Oldroyd, B. 2010. Interspecific and conspecific colony mergers in the dwarf honey bees Apis andreniformis and A. florea. Insectes Sociaux, 57, 251-255. 